\title{
Comparison of Oral Glucocorticoid and Only Analgesics in the Treatment of Idiopathic Frozen Shoulder
}

\author{
Amit Lakhani ${ }^{*}$, Karan Alawadhi², Saurabh Jain², SM Bhatnagar ${ }^{3}$ \\ ${ }^{1 *}$ Assistant Professor, 2 Senior Resident, 3 Professor, \\ Department of Orthopaedics, M. M. Medical College, Kumarhatti, Solan, Himachal Pradesh, India.
}

\begin{abstract}
Objectives: This study aims to assess and compare the role of oral glucocorticoids and only analgesics in treating patients with idiopathic frozen shoulder.

Patients and Methods: Fifty eight patients having primary idiopathic frozen shoulder syndrome were included in this study. Secondary causes (trauma, infection) and systemic disease related to frozen shoulder were excluded. Patients were randomized into two groups: patients in the first group (18 males, 11 females; mean age 45.3 years; range 32 to 67 years) were given $0.5 \mathrm{mg} / \mathrm{kg} /$ day methylprednisolone $(32 \mathrm{mg}$ maximum dose) halved each week, ceased at the end of each month and patients in the second group (11 males, 18 females; mean age 46.5 years; range 29 to 73 years) were given only oral analgesics. Physical therapy as a home program was initiated as the pain subsided in both groups. Visual analog scale (VAS), active range of motion (ROM) of the shoulder joint and Disabilities of arm, shoulder and hand (DASH) questionnaire scores were evaluated at baseline every week for one month then at end of third, sixth month and first year.

Results: Visual analog scale, DASH and active ROM scores in both groups were significantly improved. Statistically significant
\end{abstract}

\section{INTRODUCTION}

The idiopathic form of shoulder motion loss due to capsular contractures and adhesion was termed adhesive capsulitis by Neviaser based on the observed

pathoanatomy ${ }^{1}$. Primary form of frozen shoulder is idiopathic type and most common. Systemic type is due to diabetes mellitus and has more severe and protracted symptoms. Secondary type has clear primary pathology and require treatment of underlying cause $^{2}$. Treatment methods include oral analgesics, oral glucocorticoids, intraarticular glucocorticoids, physiotherapy, manipulation and arthroscopic release ${ }^{3-6}$. These modalities can be used separately or in combinations but effectiveness of each of this method is different in various clinical trials ${ }^{7}$. Oral glucocorticoids and home exercise program is very

effective in first stage of frozen shoulder ${ }^{8}$ but many studies have mentioned physiotherapy alone with analgesics as good tool to relive pain and gain long term range of motion. 9,10 In this study we compared oral glucocorticoids and only oral analgesics with physiotherapy in treating primary frozen shoulder. difference was detected between steroid and only oral analgesic in terms of post-treatment VAS scores.

Conclusion: Glucocorticoids with physiotherapy is an effective treatment for idiopathic frozen shoulder.

Key Words: Idiopathic, Frozen shoulder, VAS, DASH, ROM.

\section{${ }^{*}$ Correspondence to:}

Dr Amit Lakhani,

Assistant Professor,

Department of Orthopaedics,

M. M. Medical College, Kumarhatti

Solan, Himachal Pradesh, India.

\section{Article History:}

Received: 26-07-2016, Revised: 06-08-2016, Accepted: 28-09-2016

\begin{tabular}{|l|c|}
\hline \multicolumn{2}{|c|}{ Access this article online } \\
\hline $\begin{array}{l}\text { Website: } \\
\text { www.ijmrp.com }\end{array}$ & Quick Response code \\
\hline DOI: & \\
10.21276/ijmrp.2016.2.5.051 & \\
\hline
\end{tabular}

\section{MATERIALS AND METHODS}

The study plan was approved by our institutional review board. We included 58 patients (29 male and 29 female) of primary frozen shoulder in our study on OPD basis. Routine blood investigation and shoulder $X$ ray was done to rule out systemic and secondary cause respectively. Detailed shoulder and general physical examination was done. They were randomly divided into two groups. Patient in first group had 18 male, 11 female (32 to 67year with mean age 45.2) and second group had 11 male,18 female (29 to 73 year with mean age 46.5). Group A was given tab methylpredinslone $0.5 \mathrm{mg} / \mathrm{kg} /$ day (max dose $32 \mathrm{mg} /$ day) halved at each week and ceased at end of month. To mimic the diurnal rhythm of the blood cortisone level glucocorticoid was administered every morning. Paracetamol was given to control pain (max. dose of 2 gram). B group was given only paracetamol. Physiotherapy at home was started as soon as pain subsided. All patients were reviewed at weekly interval for one month than third, sixth and twelve month. 
Shoulder ROM (range of motion) was measured with goniometer at each visit. VAS (visual analogue pain scale) and DASH score were also recorded at each visit. Patients were followed for an interval of 12 months. An experienced physiotherapist trained all patients and exercise regime was checked at each visit. Exercise program consisted of active gravity assisted exercise and capsular stretching exercises at initial visit to gain range of motion.

Hot fomentation or cryotherapy (ice packs) was given to relieve pain. In some case taping of shoulder was done for pain relief and shoulder stabilization. As pain subsided, we switched to shoulder strengthening exercises.

Patients in both the groups improved significantly. We used visual analogue scale (VAS), ROM and DASH score to compare results. There was statistically significant difference in both groups.

\section{RESULTS}

Patients were followed up for a period of one year. No immunosuppressive or gastrointestinal side effects were seen. All patients were able to regain normal house activity after one year. Mean pre and post treatment VAS score was 7.7 and 2.5 in first group at first month. Mean pre and post treatment VAS score was 7.9 and 3.4 was in second group at first month. The change in VAS score was statistically significant at the end of one year. The mean difference is significant at 0.05 level. We find that at least some of the measures of visits differ significantly from each other as tested with the repeated-measures ANOVA at $p \leq .05$. DASH score and mean ROM given in table2 and table 3 respectively. All patients achieved full active and passive range of motion. This achievement was faster in A group (table 1)
Table 1: Mean VAS score (Group A)

\begin{tabular}{lccc}
\hline & Mean & $\begin{array}{c}\text { Std. } \\
\text { Deviation }\end{array}$ & N \\
\hline 1Visit A & 7.757 & .9666 & 28 \\
2 Visit A & 4.086 & .5720 & 28 \\
3 Visit A & 3.000 & .4776 & 28 \\
4 Visit A & 2.575 & .4248 & 28 \\
5 Visit A & 1.889 & .3594 & 28 \\
3m Visit A & 1.636 & 2.0453 & 28 \\
6m Visit A & .632 & .1124 & 28 \\
12m Visit A & .293 & .1215 & 28 \\
\hline
\end{tabular}

Table 2: Mean VAS score (Group B)

\begin{tabular}{lccc}
\hline & Mean & $\begin{array}{c}\text { Std. } \\
\text { Deviation }\end{array}$ & N \\
\hline 1 Visit B & 7.9828 & .74262 & 29 \\
2 Visit B & 6.3793 & .68211 & 29 \\
3 Visit B & 4.9966 & .43135 & 29 \\
4 Visit B & 3.3483 & .34808 & 29 \\
5 Visit B & 2.0379 & .29811 & 29 \\
3m Visit B & 1.1172 & .21559 & 29 \\
6m Visit B & .6517 & .20809 & 29 \\
12m Visit B & .2966 & .11797 & 29 \\
\hline
\end{tabular}

Table 3: DASH score

\begin{tabular}{lcccccc}
\hline Visit & \multicolumn{3}{c}{ Mean Group A } & \multicolumn{3}{c}{ Mean Group B } \\
\cline { 2 - 7 } & Flexion & Extension & Abduction & Flexion & Extension & Abduction \\
Initial visit & 15 & 4 & 15 & 18 & 0 & 18 \\
1st week & 24 & 7 & 30 & 20 & 5 & 25 \\
2nd week & 35 & 10 & 45 & 30 & 8 & 35 \\
3rd week & 45 & 20 & 54 & 40 & 14 & 50 \\
4th week & 65 & 30 & 90 & 55 & 22 & 76 \\
3rd month & 80 & 42 & 110 & 75 & 40 & 104 \\
6th month & 100 & 54 & 130 & 95 & 54 & 134 \\
1st year & 160 & 60 & 170 & 150 & 60 & 174 \\
\hline
\end{tabular}

Table 4: ROME score

\begin{tabular}{lcc}
\hline Duration & Mean dash group 1 & Mean dash group \\
\hline $1^{\text {st }}$ visit & 86 & 88 \\
$2^{\text {nd }}$ visit & 77 & 80 \\
$3^{\text {rd }}$ visit & 65 & 72 \\
$4^{\text {th }}$ visit & 54 & 60 \\
$5^{\text {th }}$ visit & 40 & 50 \\
$3^{\text {rd }}$ month & 30 & 32 \\
$6^{\text {th }}$ month & 15 & 18 \\
One year & 7 & 8 \\
\hline
\end{tabular}

\section{DISCUSSION}

Frozen shoulder is a condition characterized by a painful, gradual restriction of both active and passive movements of glenohumeral joint. There are three subgroups in frozen shoulder. Largest group is idiopathic and have no underlying cause. It is characterized by inflammatory contracture of shoulder capsule and ligaments, causing a reduction in intraarticular volume and limitation of glenohumeral movements ${ }^{11}$. Idiopathic frozen shoulder has three stages. It starts with pain (freezing) due to inflammation followed by restricted movement (frozen) and return of some movement (thawing) stage ${ }^{3}$.

There are numerous treatment methods mentioned in literature including NSAIDS, physiotherapy, intraarticular glucocorticoids, oral glucocorticoids and arthroscopic release. Physiotherapy and 
oral analgesics remains the first line of management in majority of cases but some studies in literature advocate use of oral glucocorticoids as first line of management ${ }^{12}$. We compared glucocorticoids and only analgesics in management of idiopathic frozen shoulder. The initial dose of oral methylprednisolone was $0.5 \mathrm{mg} / \mathrm{kg} /$ day (max dose $32 \mathrm{mg}$ ). It was halved gradually every week to avoid effect of glucocorticoid withdrawl. There are various studies in literature about dose of oral steroids and duration ${ }^{13-15}$. The preferred dose varies from $8 \mathrm{mg}$ to $30 \mathrm{mg} /$ day. We kept our dosage as per previous studies.

Limitation of daily activity and night pain is main complaint of the patient. The change in VAS score was significant in first group at the end of first month (7.32 to 3.2 in first group as compare to second. This may be due to rapid anti-inflammatory effect of glucocorticoids. ROM improvement was better in first group initially but all patients in both group achieved full range of motion at end of twelve months. There are numerous studies in literature about the side effects of glucocorticoids. But in our study we did not encounter any side effect of steroids.

Patients in both groups were advised physiotherapy by a single expert physiotherapist. Main aim of physiotherapy was to regain full range of motion

symmetrical to opposite shoulder. Patient was advised to exercise frequently. Local patients were advised to come for physiotherapy at our center. There is a study in literature by Russell $A$ which suggested better physiotherapy outcome in hospital based exercise program rather than home ${ }^{16}$. But in our study we did not find out much difference as in other studies.

Idiopathic frozen shoulder is a condition, in which no definitive protocol is suggested in literature. But it is one of the most common orthopedic problems. In this study we tried to compare effectiveness of glucocorticoids to analgesic in idiopathic frozen shoulder. In conclusion oral glucocorticoids are more effective in getting pain relief in initial stage of frozen shoulder. Physiotherapy is essential in both groups for regain full range of motion.

\section{REFERENCES}

1. Neviaser RJ, Neviaser TJ. The frozen shoulder: diagnosis and management. Clin Orthop 1987;223:59-64.

2. Robinson CM, Seah KT, Chee YH, Hindle P, Murray IR. Frozen shoulder. J Bone Joint Surg Br 2012. Jan; 94(1):1-9.

DOI: 10.1302/0301-620X.94B1.27093.

3. Reeves $B$. The natural history of the frozen shoulder syndrome. Scand J Rheumatol 1975;4(4):193-6.

4. Neviaser AS, Hannafin JA. Adhesive capsulitis: a review of current treatment. Am J Sports Med 2010. Nov;38(11):2346-56. DOI:10.1177/0363546509348048. Epub 2010 Jan 28.

5. Sheridan MA, Hannafin JA. Upper extremity: emphasis on frozen shoulder. Orthop Clin North Am. 2006 Oct;37(4):531-9.

6. Hannafin JA1, Chiaia TA. Adhesive capsulitis. A treatment approach. Clin Orthop Relat Res. Mar 2000;(372):95-109.
7. Rookmoneea M, Dennis L, Brealey S, Rangan A, White B, McDaid C, Harden M. The effectiveness of interventions in the management of patients with primary frozen shoulder. J Bone Joint Surg Br 2010. Sep; 92(9):1267-72. DOI:10.1302/0301620X.92B9.24282.

8. Canbulat N, Eren I, Atalar AC, Demirhan M, Eren SM, Ucak A. Nonoperative treatment of frozen shoulder: oral glucocorticoids. Int Orthop 2015. Feb; 39(2):249-54. Epub 2015 Jan 10. DOI: $10.1007 / \mathrm{s} 00264-014-2650-1$.

9. Guyver PM, Bruce DJ, Rees JL. Frozen shoulder - A stiff problem that requires a flexible approach. Maturitas 2014 May; 78(1):11-6. Epub 2014 Feb 28.

DOI:10.1016/j.maturitas.2014.02.009.

10. Kavanaugh A, Wells AF. Benefits and risks of low-dose glucocorticoid treatment in the patient with rheumatoid arthritis. Rheumatology (Oxford). 2014 Oct; 53(10):1742-51. Epub 2014 Apr 10. DOI:10.1093/rheumatology/keu135.

11. Hand GC, Athanasou NA, Matthews T, Carr AJ. The pathology of frozen shoulder. J Bone Joint Surg Br. 2007 Jul; 89(7):928-32.

12. Nazan Canbulat, Ilker Eren, Ata Can Atlar, Mehmat Demirhan, Sule Meral Eren, Ayla Ucak. Nonoperative treatment of frozen shoulder: oral glucocorticoids. SICOT 2015; 39:249-254.

13. Binder A, Hazleman BL, Parr G, Robert S. A controlled study of oral prednisolone in frozen shoulder. $\mathrm{Br} \mathrm{J}$ Rheumatol 1986. 25(3):288-292.

14. Buchbinder R, Green S, Youd JM, Johnston RV. Oral steroid for adhesive capsulitis. Cochrane Database syst rev 2006; (4):CD006189. Doi:10.1002/14651858.CD006189

15. Buchbinder R, Hoving JL, Green S, Hall S. Forbes A, Nash P. Short course prednisolone for frozen shoulder. A randomized double blind, placebo controlled trial. Ann Rheum Dis2004; 63(11):1460-1469.DOI:10.1136/ard. 2003.018218.

16. Russell S, Jariwala A, Conlon R, Selfe J, Richards J, Walton M. A blinded, randomized, controlled trial assessing conservative management strategies for frozen shoulder. J Shoulder Elbow Surg. 2014 Apr; 23(4):500-7. DOI: 10.1016/j.jse.2013.12.026.

\section{Source of Support: Nil. Conflict of Interest: None Declared.}

Copyright: (c) the author(s) and publisher. IJMRP is an official publication of Ibn Sina Academy of Medieval Medicine \& Sciences, registered in 2001 under Indian Trusts Act, 1882.

This is an open access article distributed under the terms of the Creative Commons Attribution Non-commercial License, which permits unrestricted non-commercial use, distribution, and reproduction in any medium, provided the original work is properly cited.

Cite this article as: Amit Lakhani, Karan Alawadhi, Saurabh Jain, SM Bhatnagar. Comparison of Oral Glucocorticoid and Only Analgesics in the Treatment of Idiopathic Frozen Shoulder. Int $\mathrm{J}$ Med Res Prof. 2016; 2(5):238-40. 